\title{
دور الهيئات القضائية في حماية مجال المنافسة
}

\author{
The role of judicial bodies in protecting competition
}

تاريخ الاستلام : 2019/05/07 ؛ تاريخ القبول : 2019/06/10

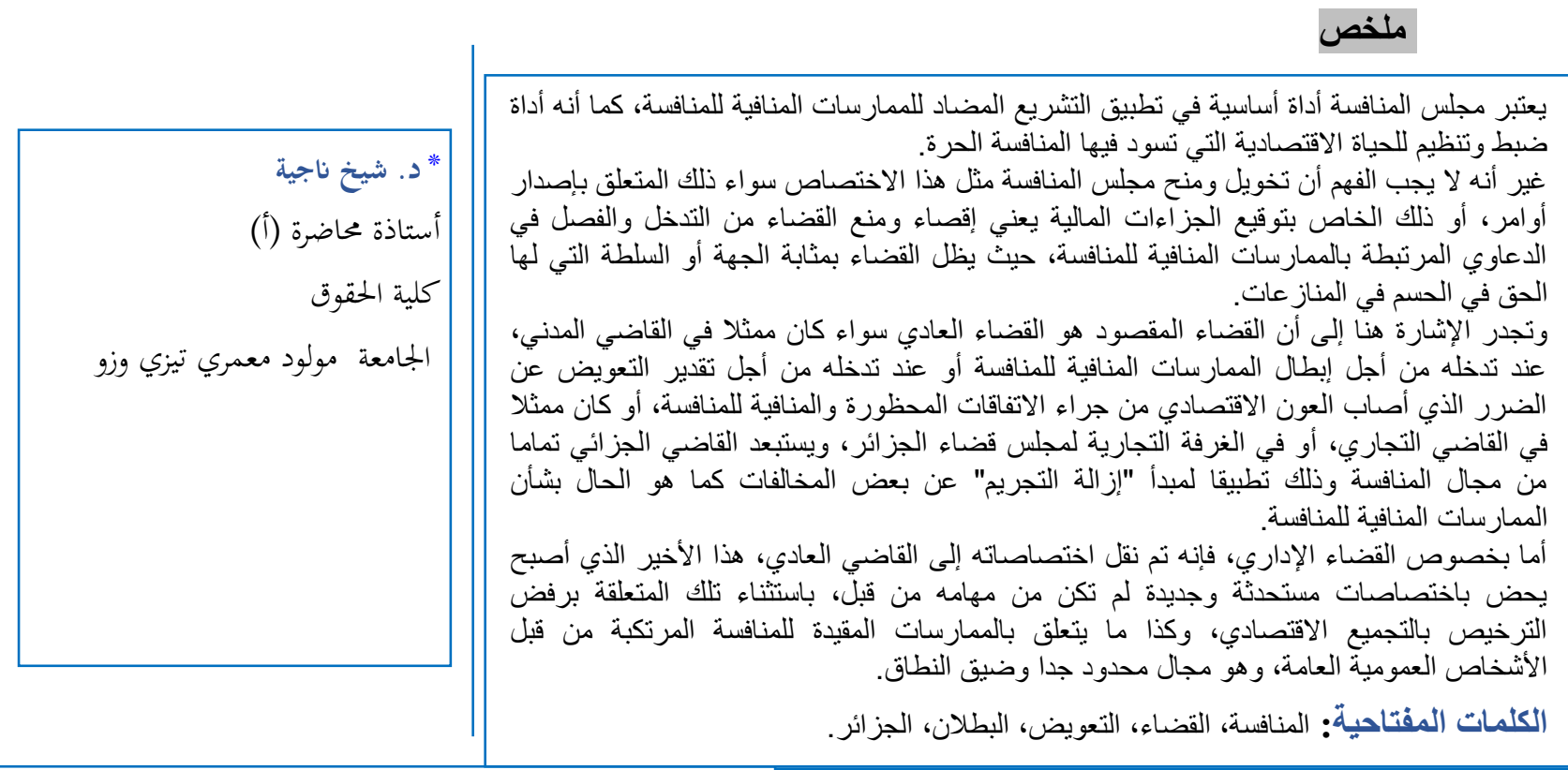

\section{Abstract}

The Competition Council is an essential tool in the application of anti-competitive legislation and is an instrument of regulation and regulation of economic life in which free competition prevails.

It should not be understood, however, that authorizing and granting the Competitiveness Council such competence, whether for issuing orders or for imposing financial sanctions, would exclude and prevent the judiciary from intervening and adjudicating cases related to anti-competitive practices, where the judiciary remains the authority or authority that has the right Dispute Resolution.

It should be noted here that the intended judiciary is the ordinary judiciary, whether represented by a civil judge, when it intervenes to invalidate or intervene in anti-competitive practices in order to assess compensation for damage caused to economic aid by prohibited and anti-competitive agreements, Commercial Chamber, or in the Chamber of Commerce of the Algiers District Council. The penal judge completely excludes competition from the principle of "criminalization" for certain irregularities, as is the case with anti-competitive practices.

As for the administrative judiciary, its terms of reference were transferred to the ordinary judge, the latter being brought up with new and new terms of reference that were not previously his duties, except those relating to the rejection of the economic collection license, as well as the practices restricting competition by public officials, Very limited and narrow domain.

Keywords: Competition, Judiciary, Compensation, Invalidity, Algeria.

\section{Résumé}

Le Conseil de la concurrence est un outil essentiel pour l'application d'une législation anticoncurrentielle et un instrument de régulation et de régulation de la vie économique dans lequel la libre concurrence prévaut.

Toutefois, il ne faut pas comprendre que l'autorisation et l'attribution du Conseil de la concurrence, telles que l'émission d'ordonnances ou l'imposition de sanctions financières, excluent et empêchent le pouvoir judiciaire d'intervenir et de statuer sur des affaires de pratiques anticoncurrentielles, Résolution de litige. Il convient de noter ici que l'élimination vise le pouvoir judiciaire ordinaire, qu'il soit représenté par un juge civil, lorsqu'il intervient pour invalider ou intervenir dans des pratiques anticoncurrentielles afin de déterminer le montant des dommages causés à une aide économique par des accords interdits et anticoncurrentiels, Chambre de commerce ou à la chambre de commerce du conseil de district d'Alger: le juge pénal exclut complètement la concurrence du principe de "criminalisation" de certaines irrégularités, comme dans le cas des pratiques anticoncurrentielles.

En ce qui concerne le pouvoir judiciaire administratif, son mandat a été transféré au juge ordinaire qui a été saisi de mandats nouveaux et nouveaux qui n'étaient pas auparavant de son ressort, à l'exception de ceux relatifs au rejet de la licence de recouvrement économique et aux pratiques restrictives des agents publics. Domaine très limité et étroit.

Mots clés: concurrence, judiciaire, indemnisation, invalidité, Algérie.

* Corresponding author, e-mail: nadjya.chikh @ yahoo.fr 
مقدمة:

يُعتبر إنتاء مجلس المنافسة في الجزائر بمثابة حدثا مميز ا، لما له من أهمية في

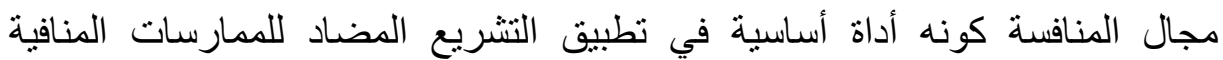

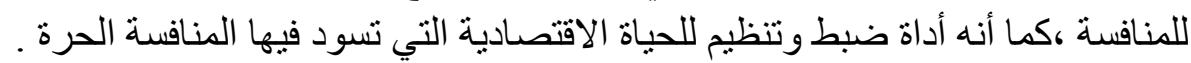

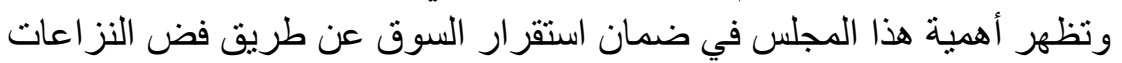

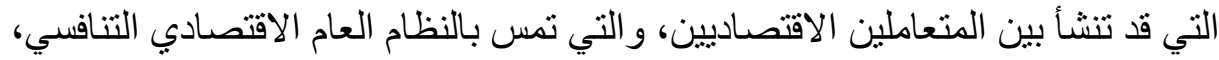

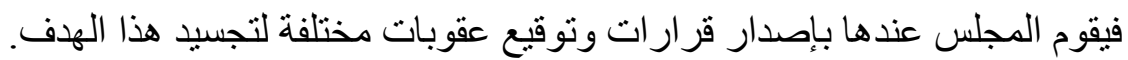

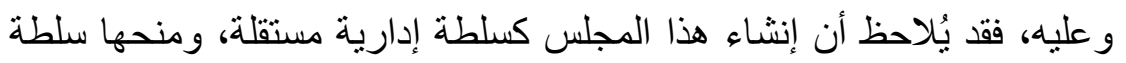

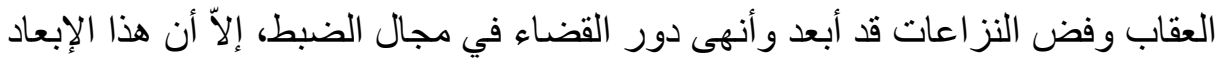

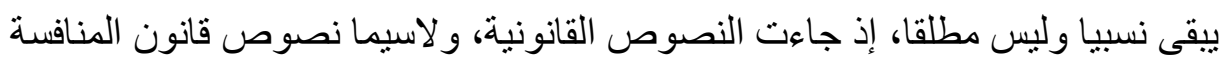
بموجب الأمر رقم 03-03 المعدل و المتمم(1)، لتؤكد أنّ مجلس المنافسة ليس ليس الوحيد الذي يملك الاختصاص في تطبيق تشريع الممارسات المنافية للمنافسة، لكون صلاحت الدياته

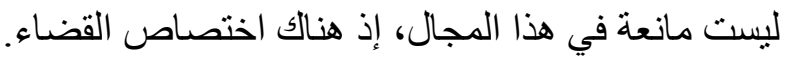

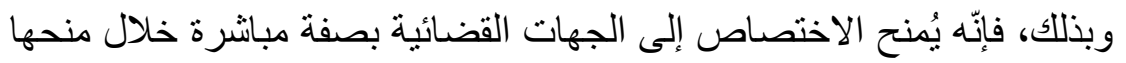

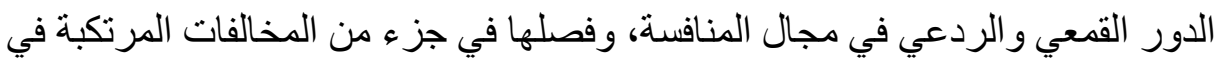

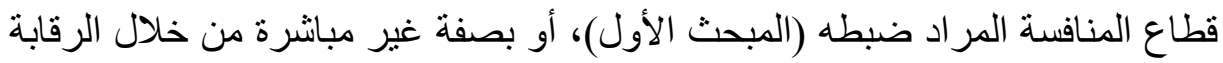
على أعمال مجلس المنافسة و على القرار ات المتخذة من طرفه فله (المبحث الثاني). وما تجدر الإشارة إليه هنا، هو أنه، وبالر غم من تنوع وتعدد الجهات التهات القضائية

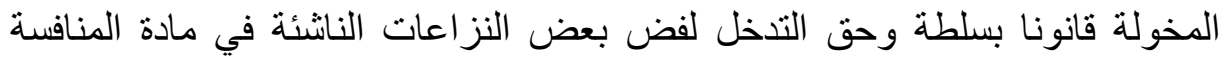

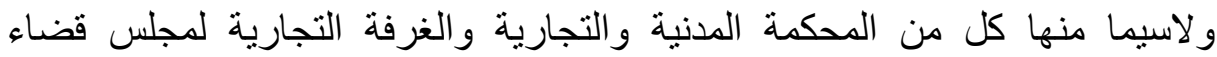

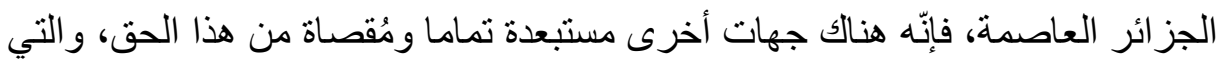

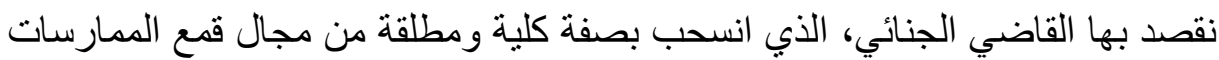

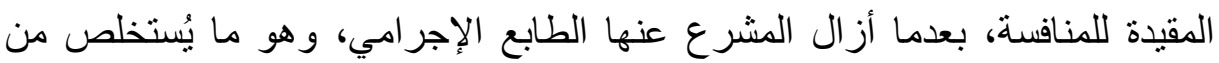

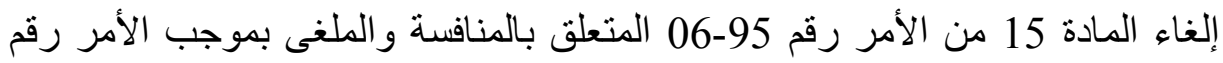

03-03 المعدل و المتمح.

وبناءً على كل ما سبق يمكن طرح الإشكالية الآتية:

فيما تكمن خصوصية المتابعة القضائية المكرّسة للفصل فلية في منازعات

المنافسة؟

و ومن أجل الإجابة عن الإثكالية ،ارتأينا اقتر اح الخطة الآتية_

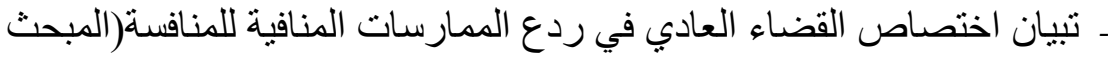

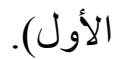

ـ ـ ثم تبيان اختصاص القضاء في الرقابة غلى قرارات مجلس المنافسة(المبحث

الثناني).

\section{المبحث الأول - الاور القمعي للقاضي العادي في ترقية قواعد المنافسة:}

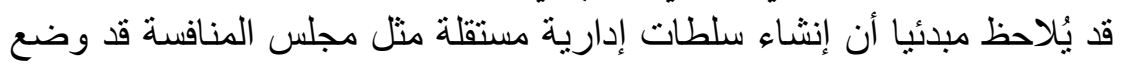
دور القاضي جانبا، وهي فكرة غير صحيحة بصفة مطلقة، إذ، وبالر غم من تمتع مجلس إنس 
المنافسة بصلاحيات و اسعة في متابعة ومعاقبة الممارسات المقيدة للمنافسة تنفيذا لدوره

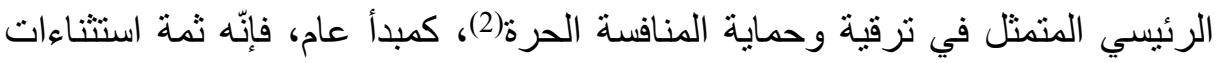
تطبّق في هذا المجال، وذلك بإخر اج بعض وحض الاختصاصات من نطاق صلاحيات المجلس ومنحها للجهات القضائية.

على إثر ها، يكون للقضاء صلاحية فض النزاعات المتعلقة بالممارسات المخلة بحرية المنافسة وذللك بدعويين مختلفتين، وهما دعوى البطلان (المطلب الأول)، وكذا دعوى التعويض عن الأضرار (المطلب الثاني). المطلب الأول - إبطال الممارسات المقيدة للمنافسة:

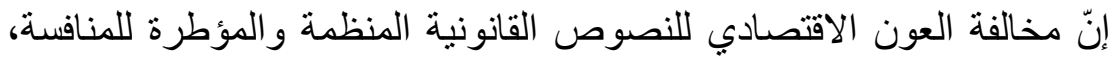

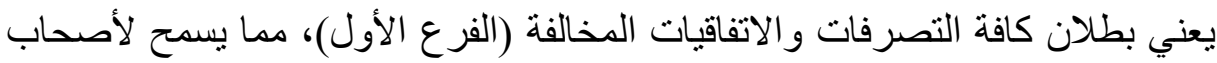
الحق التمسك بالبطلان و اللجوء إلى القضاء للمطالبة بتقريره (الفرع الثاني). الفرع الأول - نطاق تطبيق البطلان:

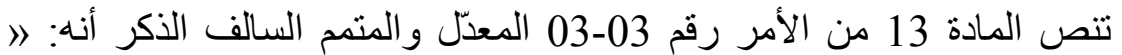

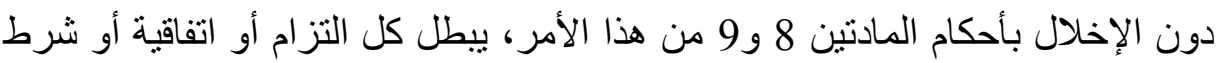
تعاقدي يتعلق بإحدى الممارسات المحظورة بموجن المبن المو اد 6 و 7 و و10 و 11 و12 أعلاه

يُستخلص من استقراء البند أعلاه، أن جزاء البطلان ينصب على مجمل

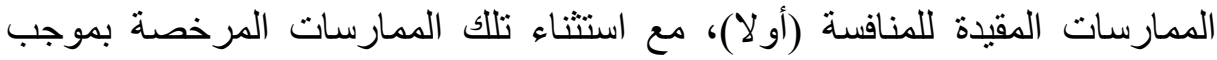
المادتين 8 و9 من مجال البطلان (ثانيا). أولا - سريان البطلان على كافة الممارسات المقيدة للمنافئن المانة

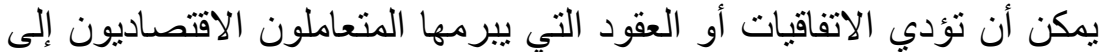

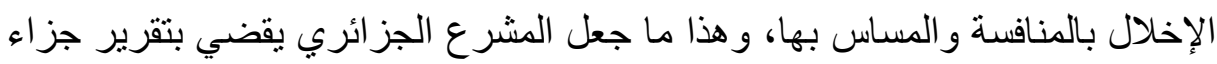

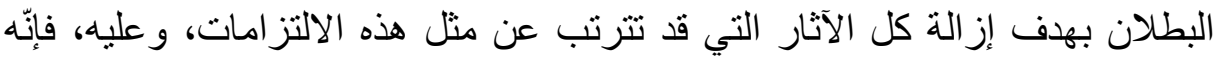
يُبطل بقوة القانون كل التزام أو اتفاقية أو شرط تعاقدي متعلق بإحدى الممارسات

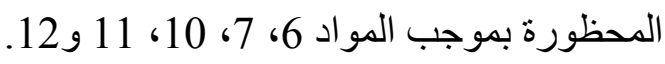
ويلاحظ من خلال التمعن في نص المادة 13 السابقة، أنّ المشرع الجزائري لم

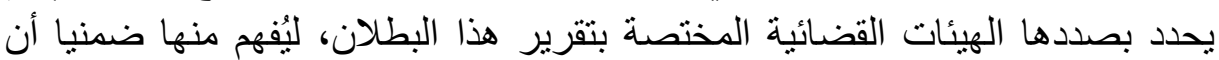

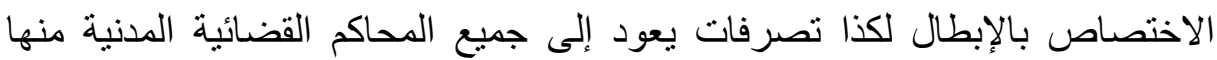

$$
\text { ثانيا - عدم سريان البطلان على الممارسات المرخصة: }
$$

$$
\text { و التجارية. }
$$

إذا كان الأصل هو بطلان كل الممارسات المحظورة، و لاسيما منها تلك الكان

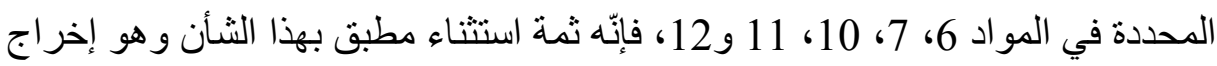

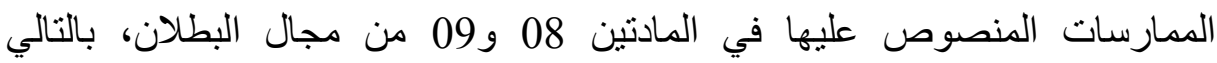

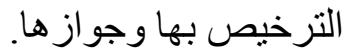

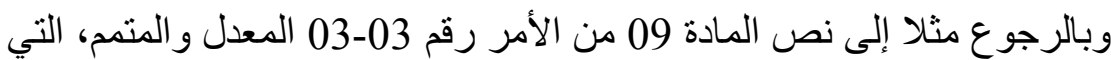

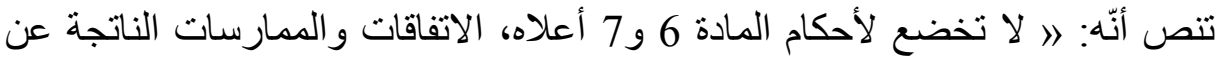
تطبيق نص تشريعي أو نص تنظيمي أخذ تطبيقا له. لأه

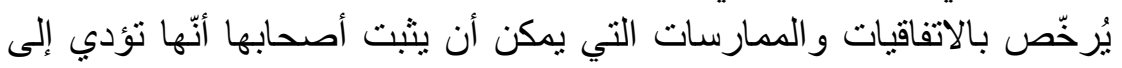

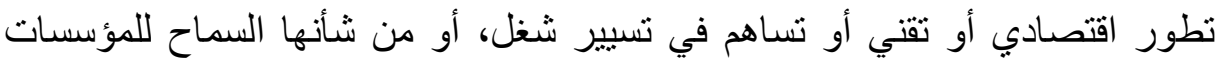


الصغيرة و المتوسطة بتعزيز وضعيتها التنافسية في السوق، ولا تستفيد من هذا الحكم

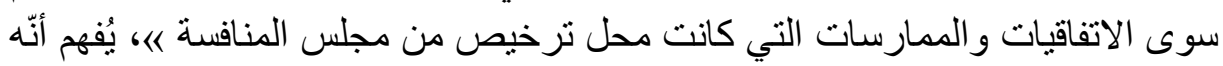

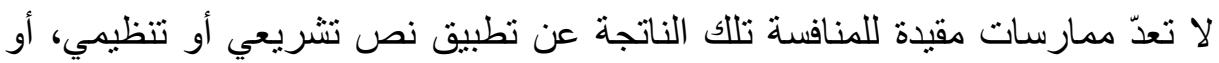

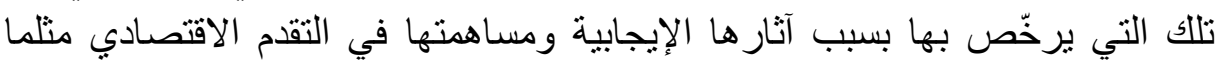
حددته الفقرة 02 من المادة 09 أعلاه. الفرع الثاني - أصحاب الحق في التمسك بادة اعلبطلان:

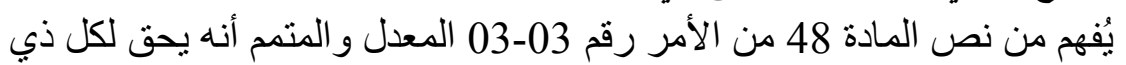

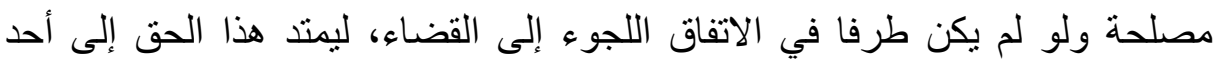

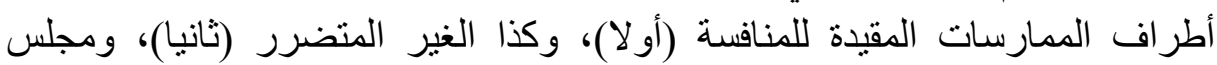

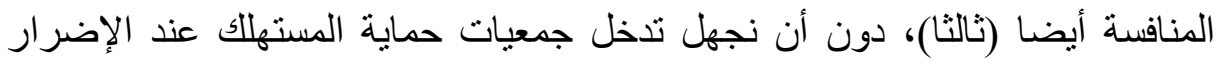

بمصالحها الجماعية لطلب البطلان (رابعا) ،أو الوزير المكلف بالتجارة التهات خامسا).

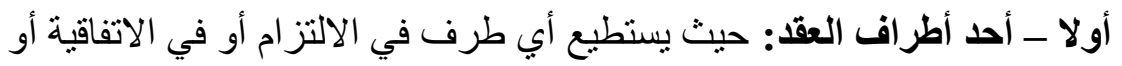

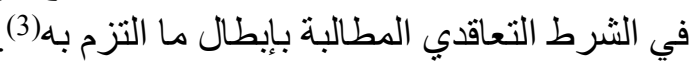

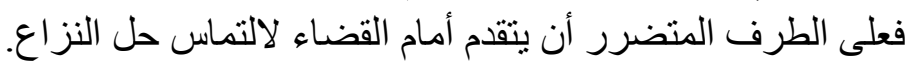

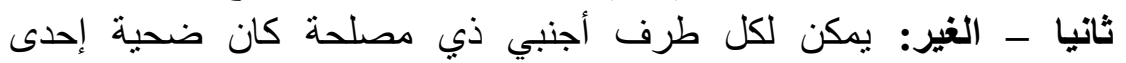
الممارسات المقيدة للمنافسة رفع دعوى البطلان.

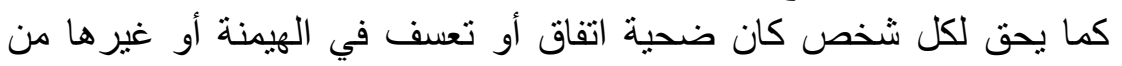

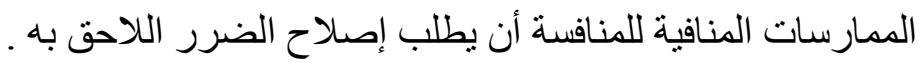

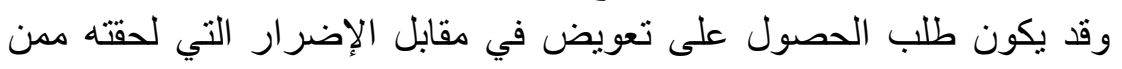
جر اء هذا العقد أو يتعلق الطلب بمنع الاستمر ار في مثل هذه فئل الممارسات.

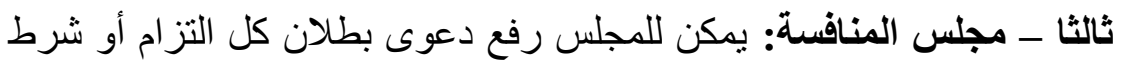

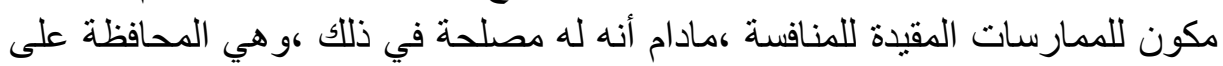
المنافسة و على الصالح العام. ويكون ذلك عندما يتضمن الملف المعروض عليه التزامات منافية للمنافسة، حيث يتولى مجلس المنافسة رفع دعوى البطلان، وذللك لكون المحاكم المدنية والتجارية

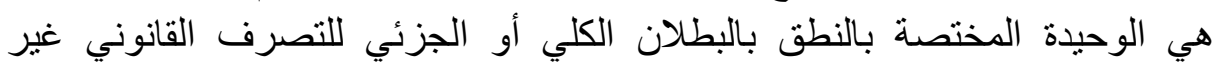
رابعا - جمعية حماية المستهلك: يجب على جمعيات حماية المستهلك عدم

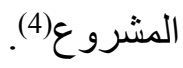

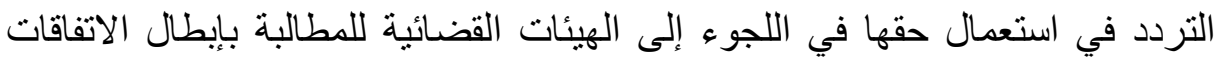

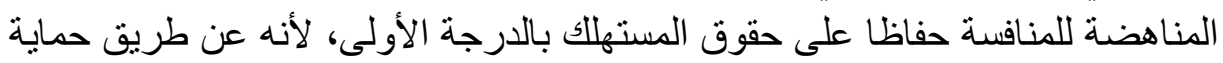

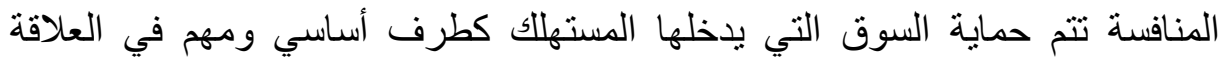

خامسا_الوزير المكلف بالتجارة: فيما يخص إمكانية وزير التجارة في رفع الماف

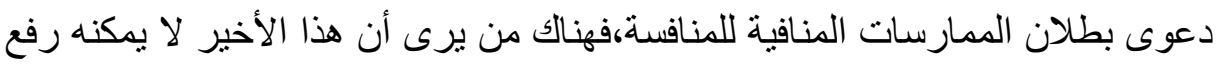

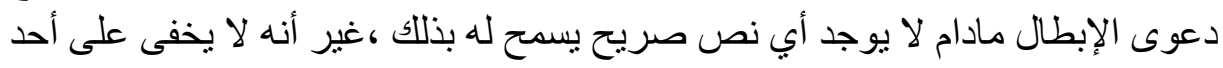

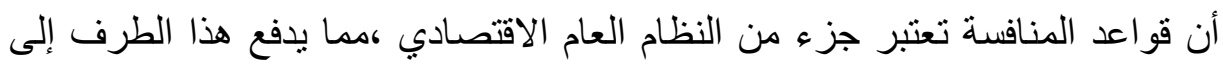
التنخل كلما تطلب الأمر ذلك. في الأخير، يمكن الإشارة إلى أنّ طلب هذا البطلان من أحد الأطر اف السابقة 
قد ينصب على العقد بأكمله أو على جزء منه فقط، ليكون البطلان جزئيا أو كليا

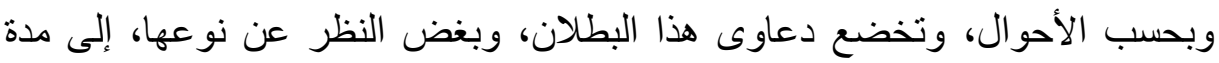
التقادم المعروفة في القو اعد العامة وهي 15 سنة، طبقا للمادة 102 فقرة 02 من القانون

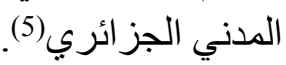

الفرع الثالث ـ الآثار المترتبة عن الطعن بالبطلان : الثان

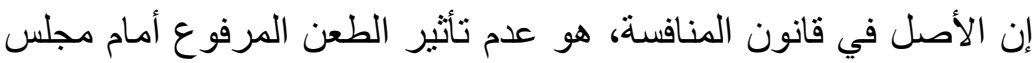

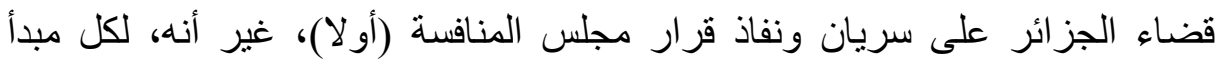
استثناء، حيث يمكن طلب وقف تنفيذ قرار مجلس المناء المنافسة (ثانيا). أولا- نفاذ قرار مجلس المنافسة كأصل:

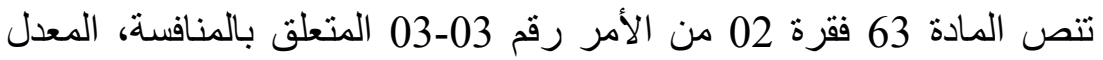

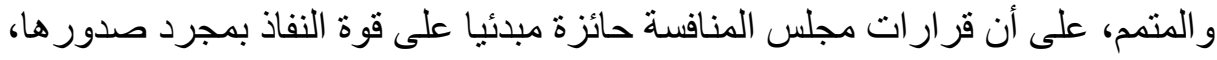

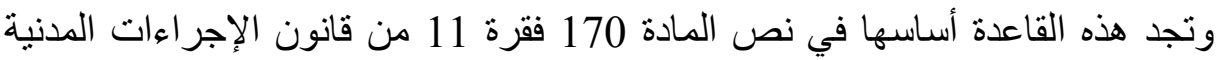

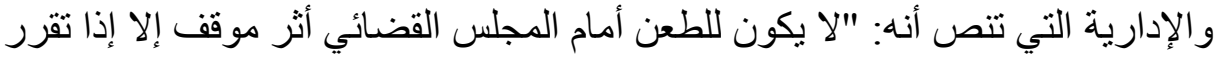

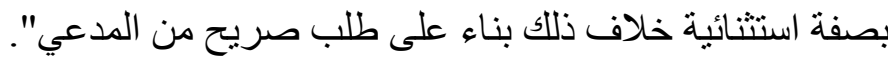

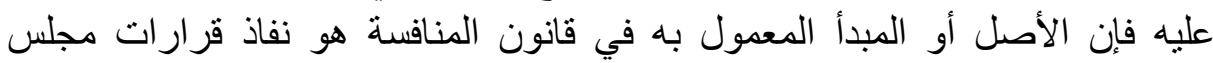
المنافسة. ثانيا- طلب وقف تنفيذ قرارات مجلس المنافسة كاستثناء:

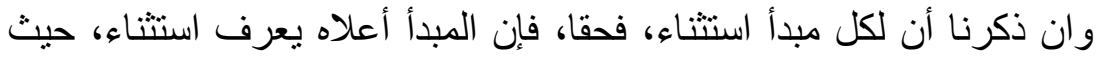
يمكن وقف تتفيذ قرار ات مجلس المنافسة.

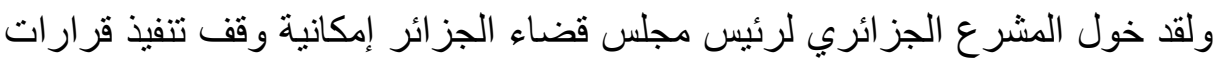
مجلس المنافسة، وذلك بشروط مر افقة لتنفيذ القرار و لاسيما إذا كان تنفيذ القرار يؤدي

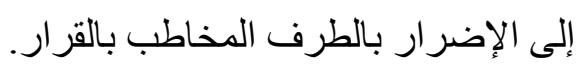

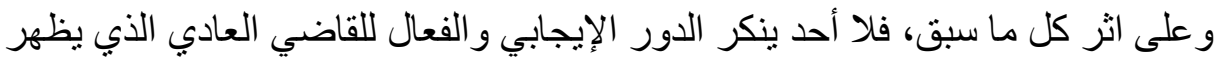

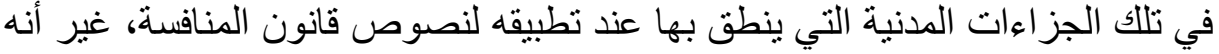

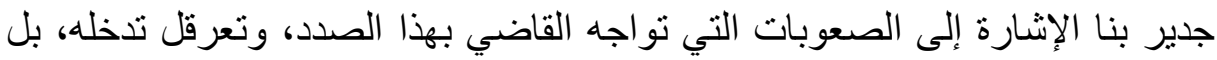

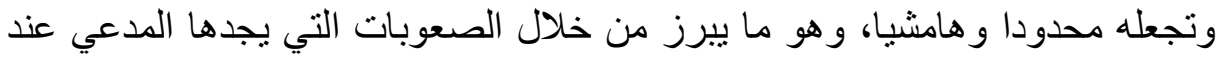

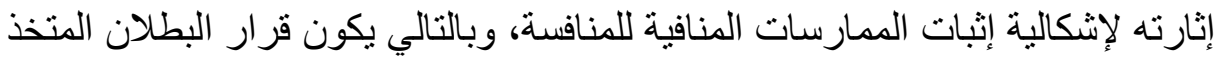

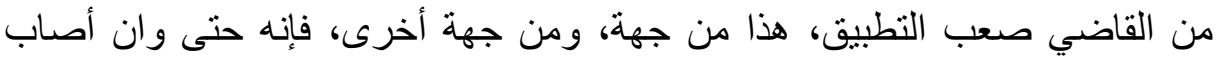
وتمكن المدعي من إثبات الممارسات المنافية للمنافسة، فإن القاضي العادي يصطام

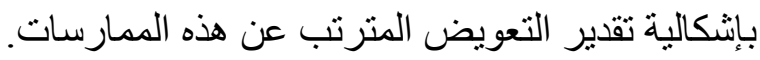

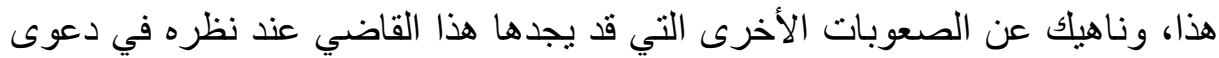

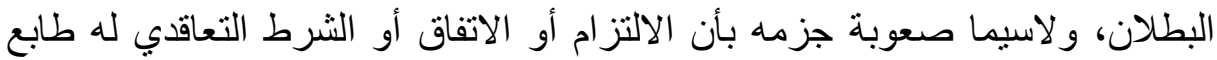

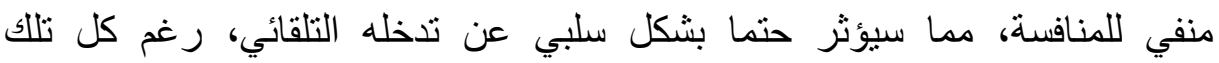

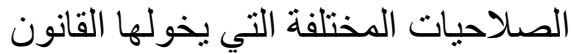
وكذا صعوبة إثبات القاضي للممارسة أنها منافية للمنافسة عند ارتباط الأمر

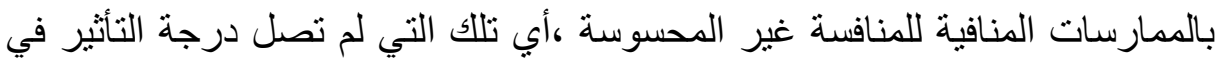
سوق معينة، وذلك بالنظر لضعف نأثير ها في السوق، فهي اتفاقات ذات الحجم الصغات الصغير

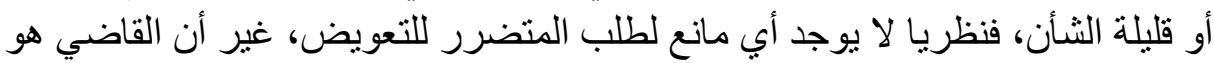
من يصعب عليه إثبات هذا الخطأ كونه لا يبلغ عتبة الحساسية. 
كما يصعب عليه تقدير التعويض كنتيجة حتمية لصعوبة تقدير الضرر في بعض الممارسات المنافية للمنافسة.

عليه، ومن أجل أداء القاضي العادي لمهامه على أكمل وجاه، فإنه لابد من أن يتوفر

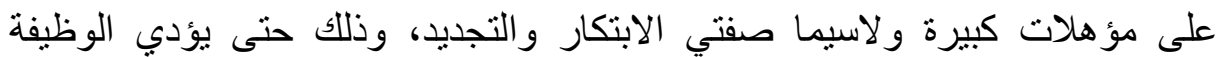
الضبطية على أكمل وجها.

إن اختصاص القاضي العادي في الرقابة هو اختصاص مستحدث، حيث كان في

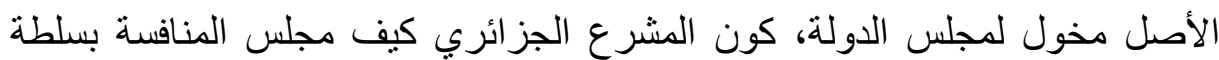
إدارية مستقلة، وتبعا لهذا الموقف فإن اختصاص النظر في الطعون ضد القرارات

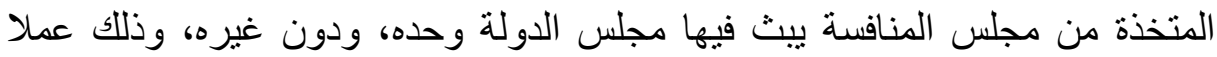

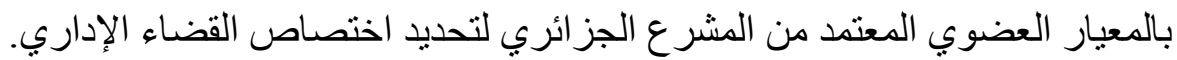

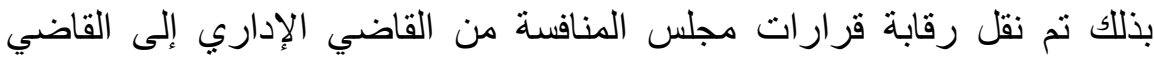

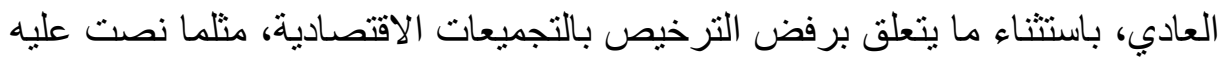
المادة 19 فقرة 03 من الأمر 03-03 السابق، وكذا ما يتعلق بالممارسات المقيدة

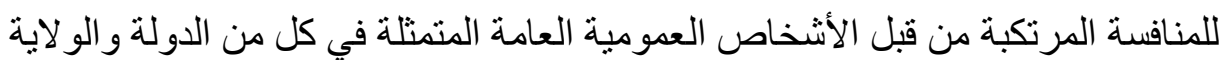

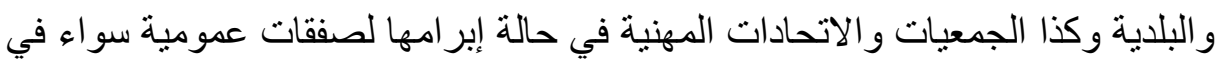
المر احل الأولية أو في مرحلة إيداع العروض، وهذا وفقا للمرسوم الرئاسي رقم 02-

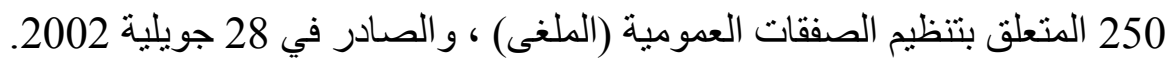
المطلب الثاني - الحكم بالتعويض عن الأضرار الناتجة عن الممارسات المقيدة

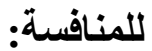

يمنح المشرع الجزائري بموجب الأمر رقم 03-03 المعدل والمتمم في المادة

48 منه الحق لكل شخص طبيعي أو معنوي متضرر نتيجة الترب ممارسة مقيدة للمنافسة

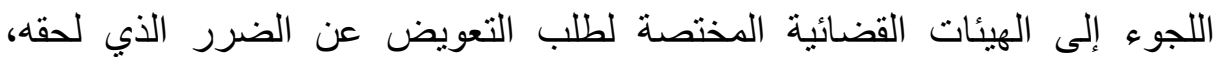

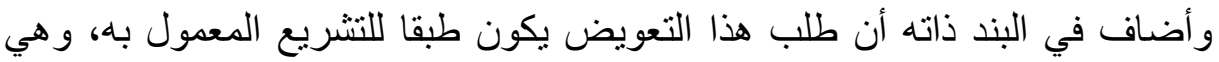

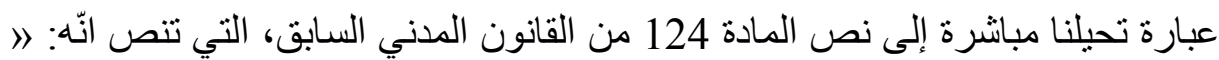

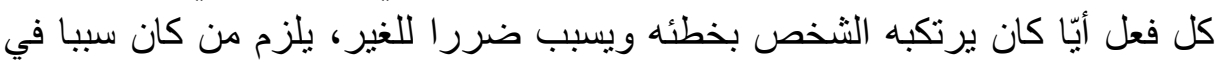
حدوثه بالتعويض «ا، ومن ثمة فإنّه لكل منضرر من جر اء ممارسة مقيدة للمنافسة الحق

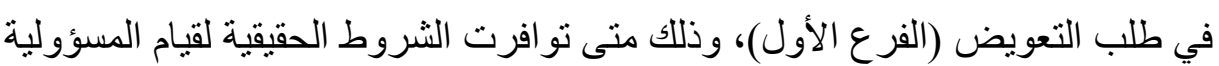
و تأسيسها (الفرع الثاني).

\section{الفرع الأول - أصحاب الحق في طلب التعويض:}

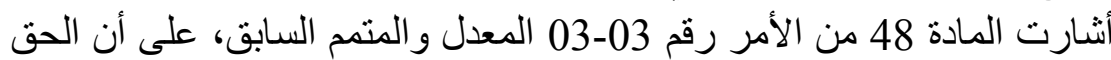
في إقامة دعوى التعويض لجبر الضرر الناتج عن ممارسة مقيدة للمنافسة قد يكون إما لإنا

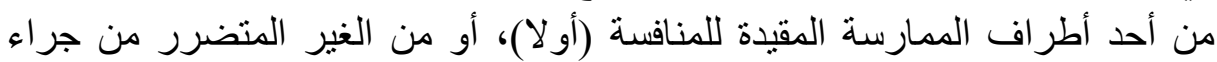

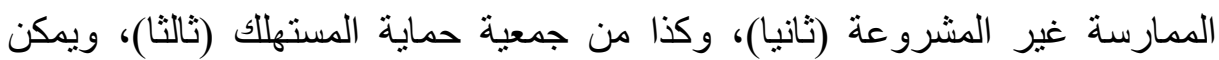

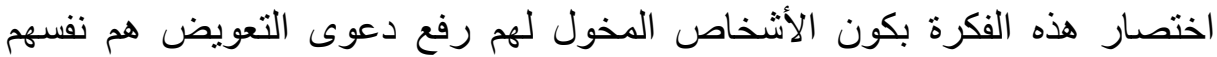

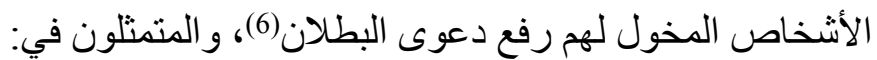

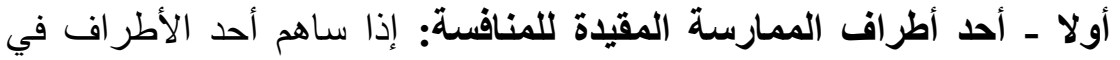

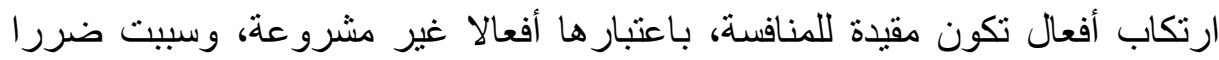

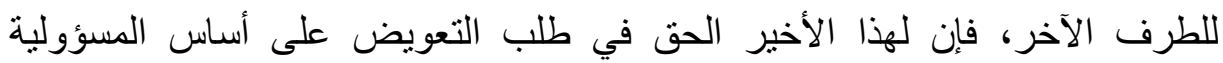


التقصيرية، كونه وقع ضحية لتعسف الطرف الآخر في استعمال حقه(7).

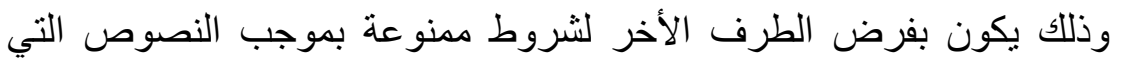
تحظر مثنل هذه الاتفاقيات.

ثانيا ـ الغير المتضرر: يجوز لكل شخص ضات ضحية لإحدى الممارسات المقيدة

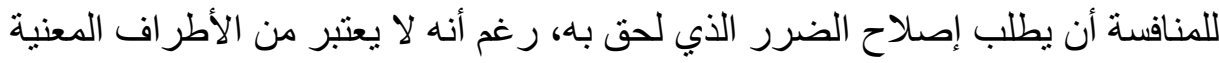
بالممارسة نفسها.

ويتم تأسيس طلب الضحية بالاستناد إلى المادة 48 من الأمر 03_03

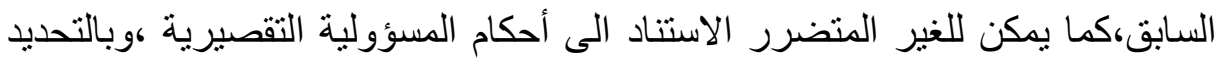

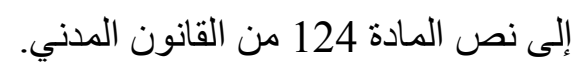
ثالثا - جمعية حماية المستهلك: يحق لجمعية حماية المستهلكين المعتمدة

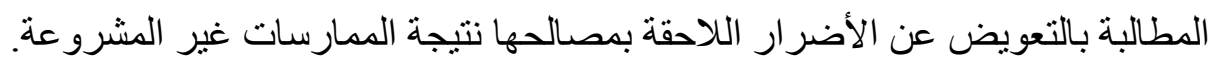

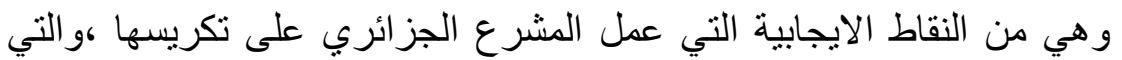

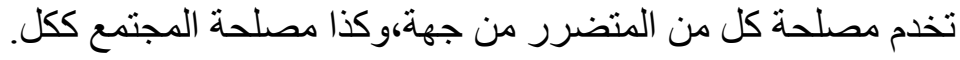

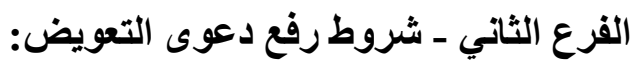

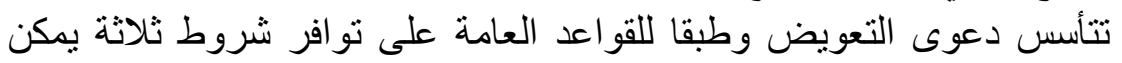

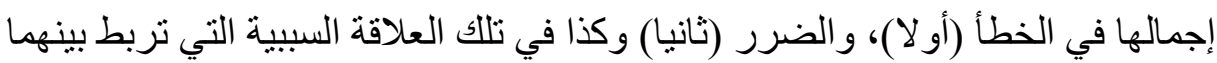

أولا ـ الخطأ: إن مسألة العون الاقتصادي تشترط أن يرتكب الخطأ الذي يتمثل

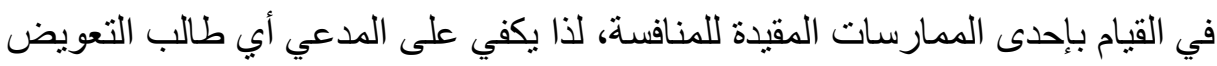
إثبات وجود تلائ الممارسة.

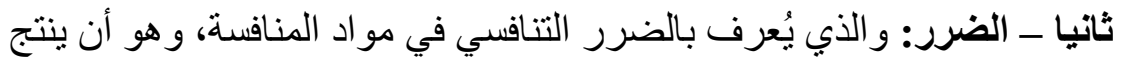

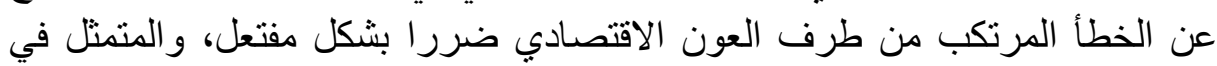
إعاقة و عرقلة حركة السوق(8). و أمام صعوبة تقدير التعويض المناسب لهذا الضرر التنافسي، فإنّه يمكن

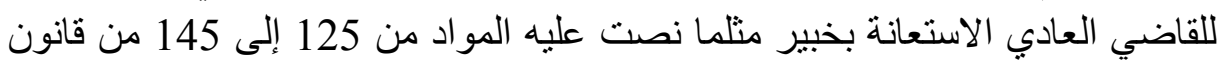

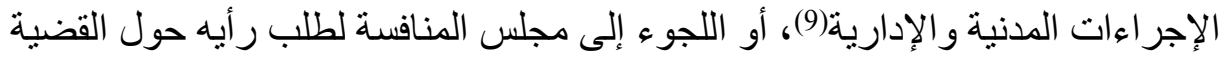

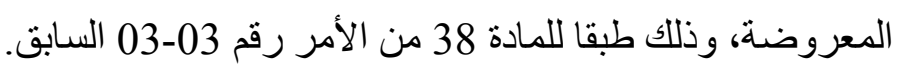

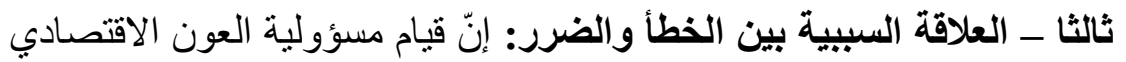

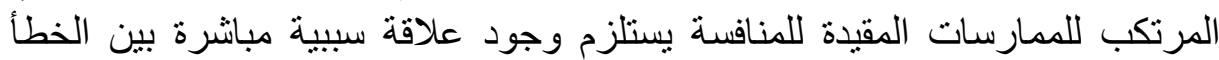
المرتكب و الضرر الناتج. و على إثر ذلك يُستخلص أنه بمجرد نو افر هذه الأركان تتحقق وتقوم مسؤولية

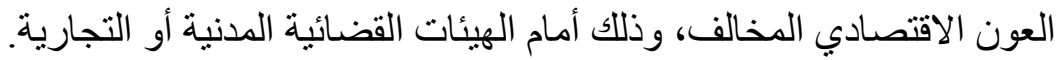

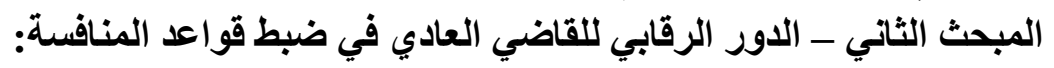

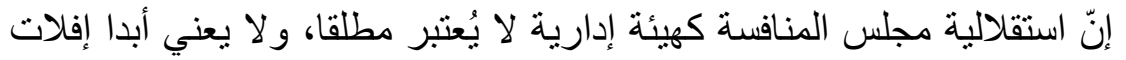

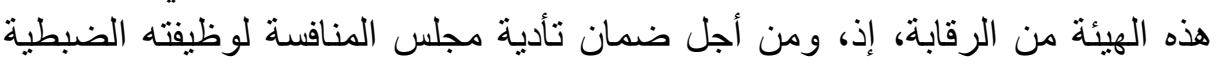

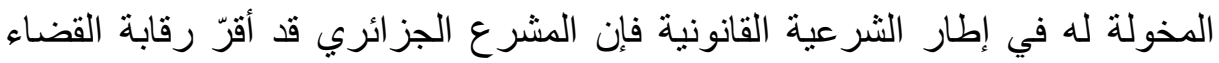
العادي على أعمال مجلس المنافسة.

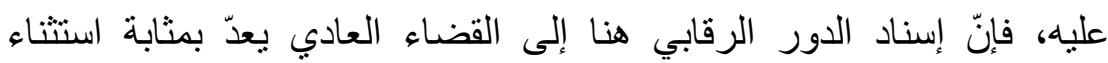

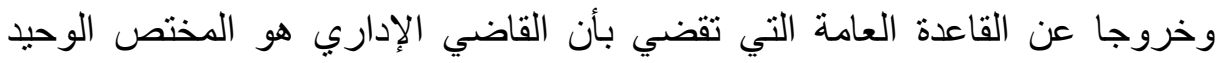




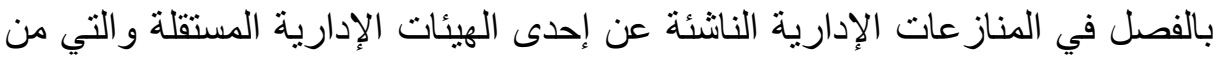

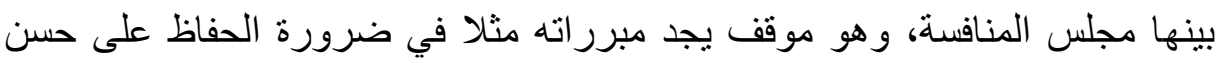

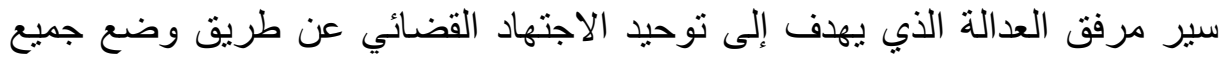

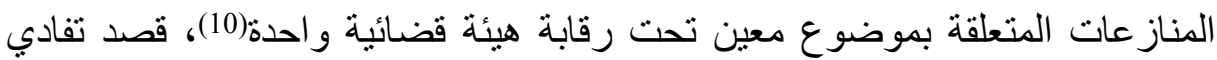

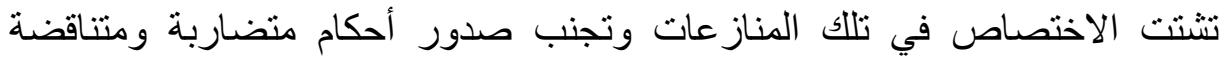

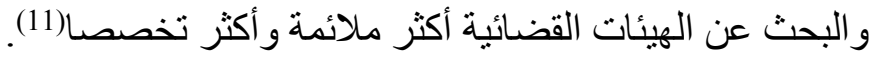

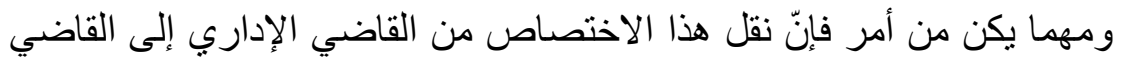

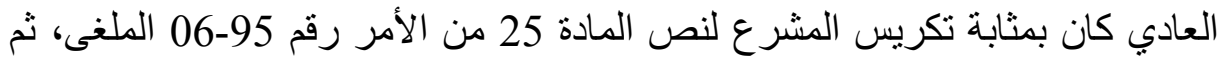

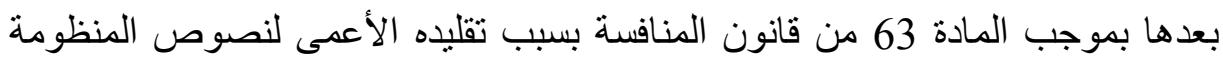
الفرنسية(12)، حيث قام المشرع الجز ائري بتبني محتوى الأمر رقم

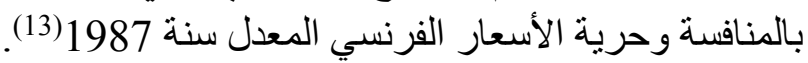

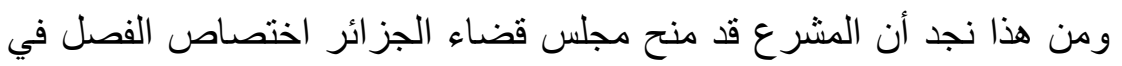

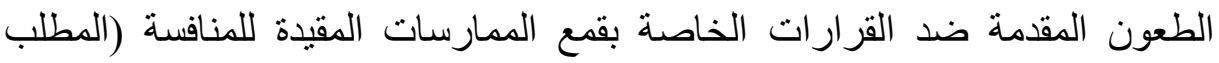
الأول)، ليتخذ بشأنها القر ار الملائم (المطلب الثناني).

المطلب الأول - خصوصية الطعن أمام مجلس قضاء الجزئ الجزائر:

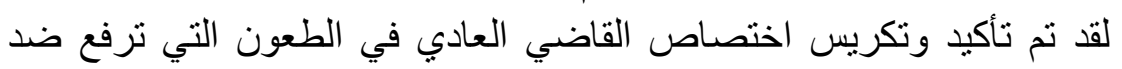

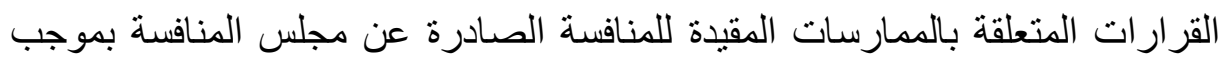

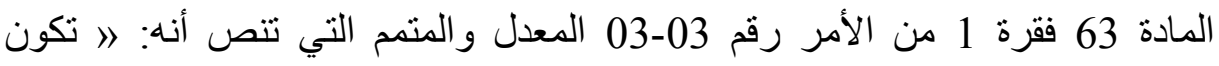

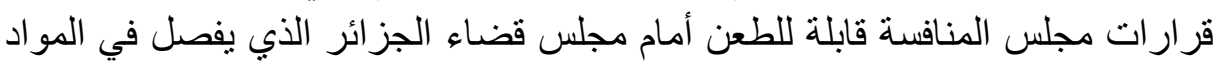

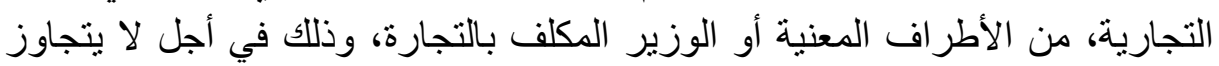

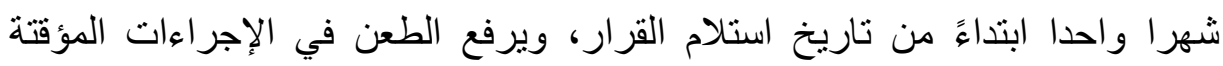

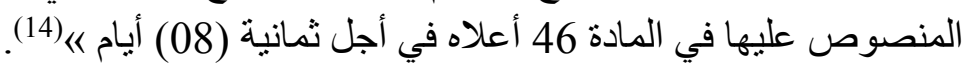

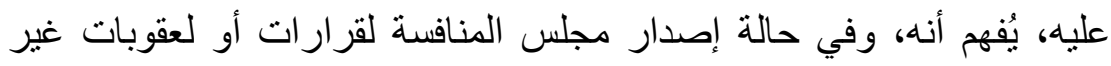

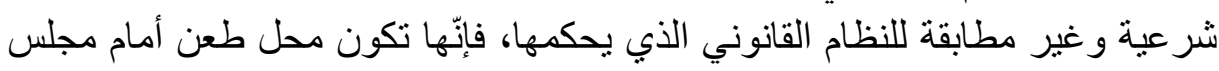

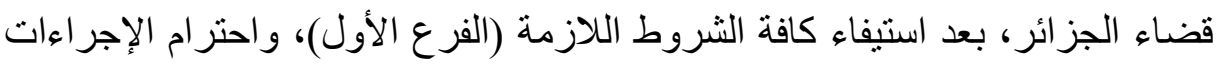

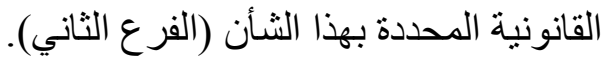
الفرع الأول - شروط الطعن في قرارات مجلس المنافسة:

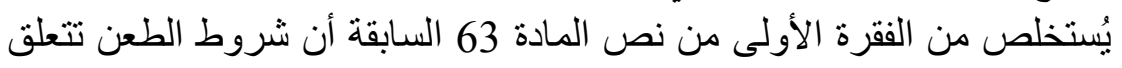

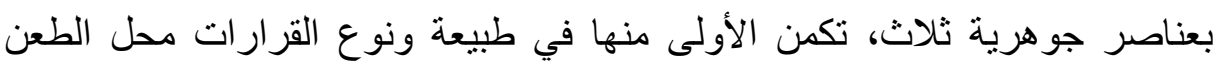

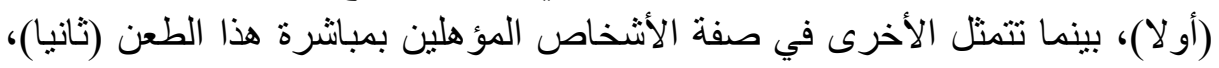
ليتحدد في الأخير آجال ومواعيد صحة الآنر هذا الطعن (ثالثا).

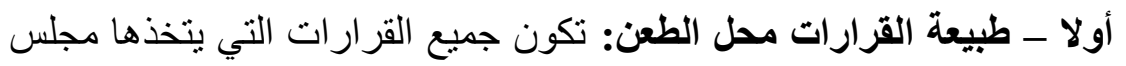

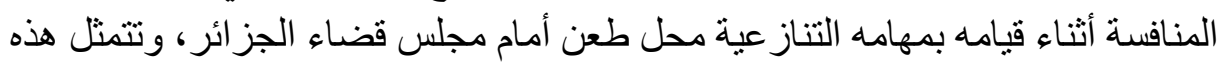

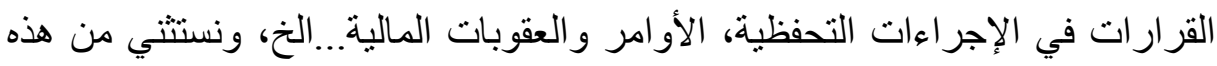

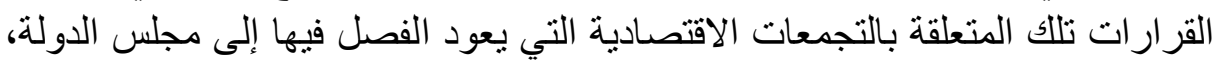

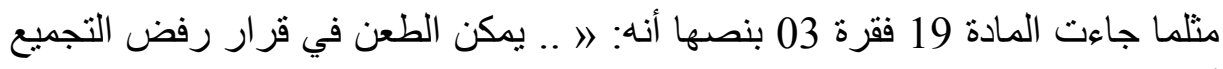

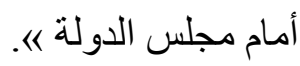
ثانيا ــ الأشخاص المؤهلون بمباشرة الطعن: يحق لكل شخص معني بالقرار 


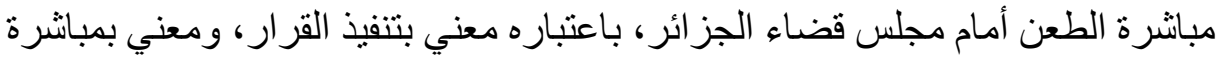

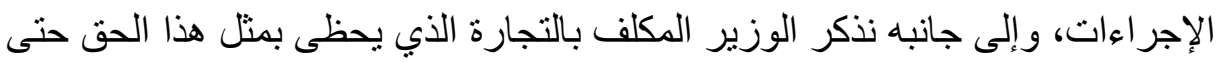
و إن كان ليس هو المخطر بـاهـ(15).

ثالثا ـ مواعيد الطعن في قرارات المجلس: تختلف آجال الطعن في قرارات

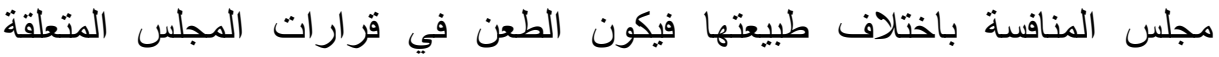
بالموضوع كقرار تسليط العقاب وتوجيه الأوامر في أجل شهر ونافئه واحد من تاريخ استلام

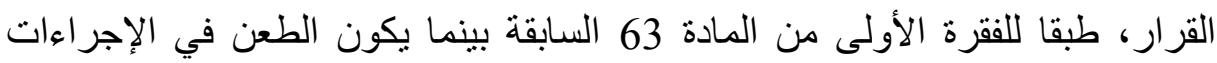
المؤقتة المنصوص عليها في المادة 46 من قانون المنافسة في أجل ثمانية (08) أيام.

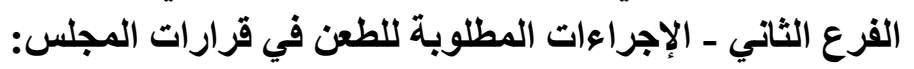

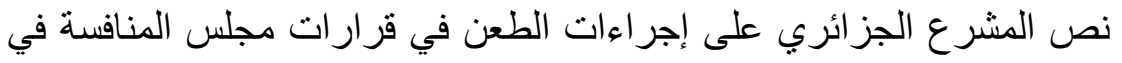

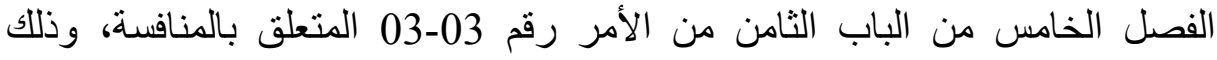

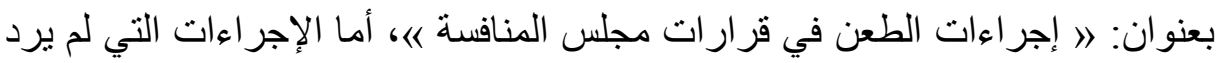

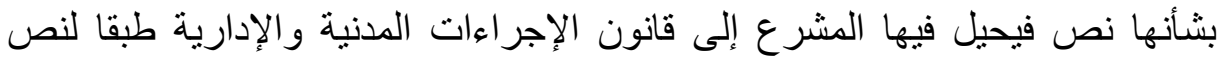

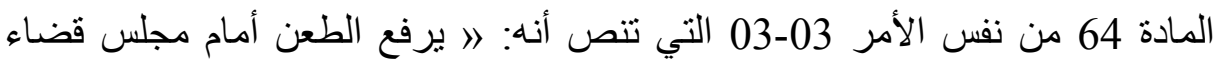

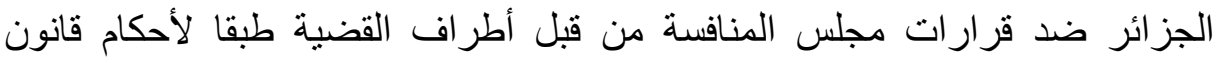

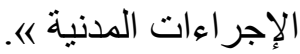

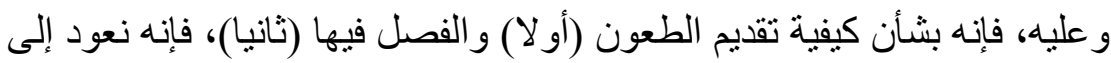

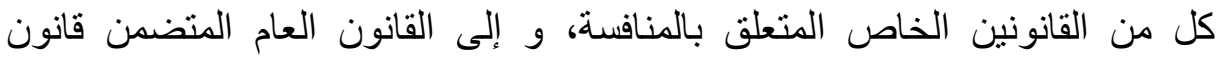
الإجراءات المدنية والإدارية في حالة وجود فراغ لإنانوني في الأول (أي في قانون المنافسة).

أولا - كيفية تقديم الطعن: نظر العدم تحديد مثل هذه الكيفية في قانون المنافسة

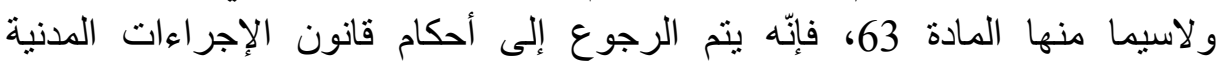

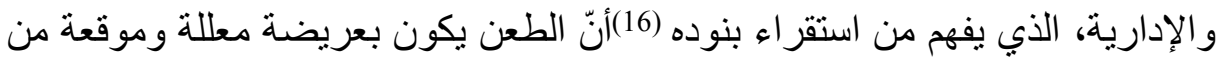

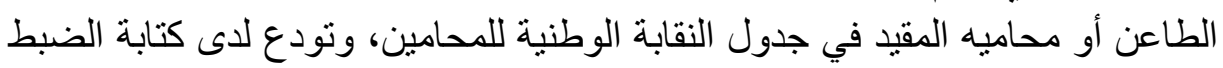

ويجب أن تكون العريضة مستوفية لجميع الثروط (هوية الطاعن، عنوانه، للمجلس القضائي.

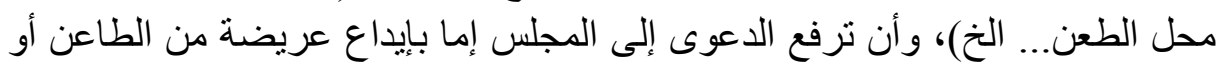

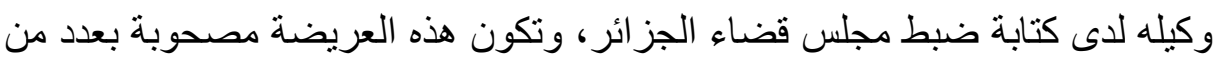

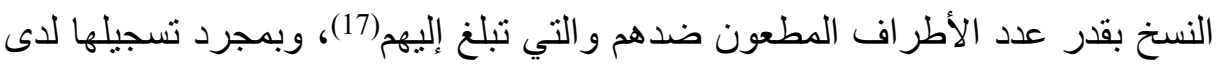

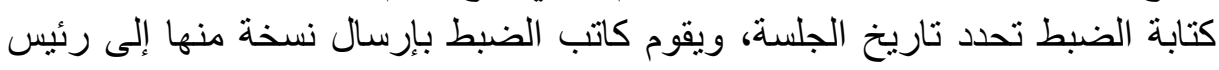

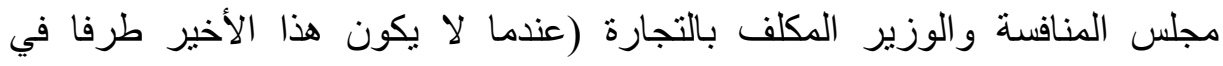

ثانيا - كيفية الفصل في الطعن: تُعرف هذه المرحلة بمرحلة التحقيق ودراسة

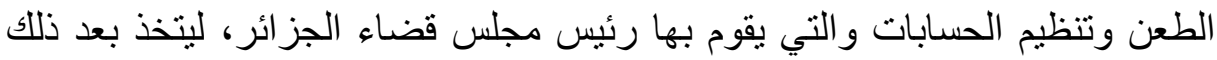

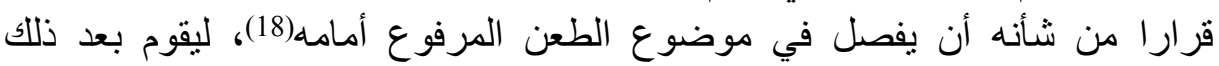

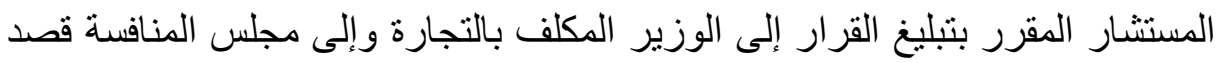

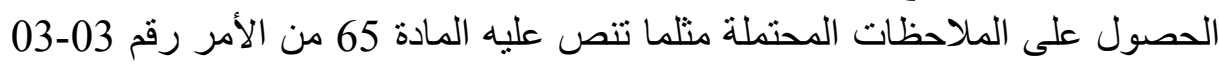

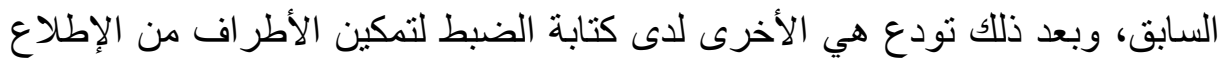

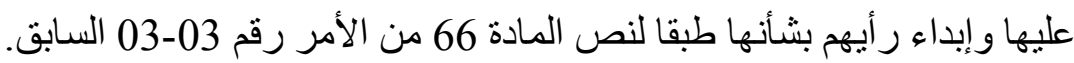


وفي الأخير يقوم مجلس قضاء الجزائر بتحديد تاريخ الجلسة والفصل في

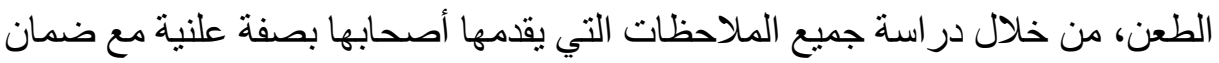
بعض الحقوق و لاسيما الحق في الدفاع بمثنل قانوني، وكذا حماية السر المهني(19).

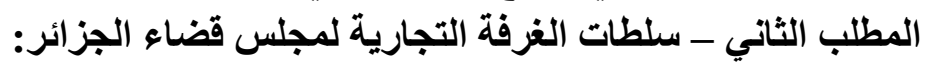

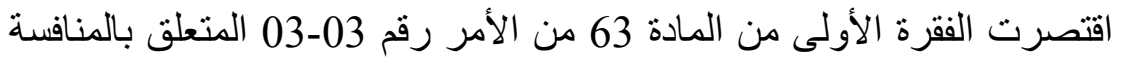

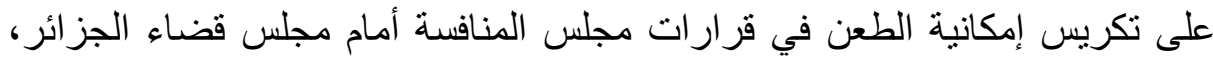

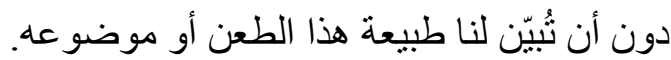

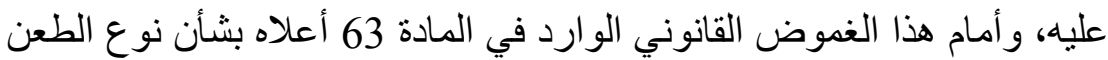

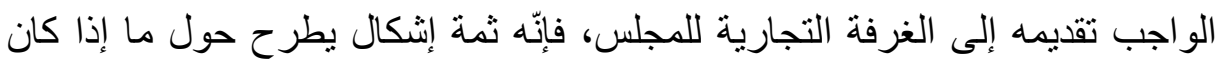

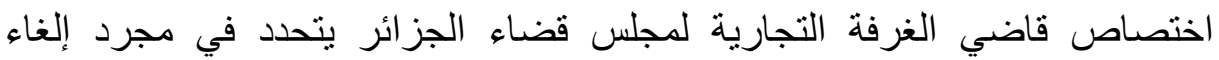

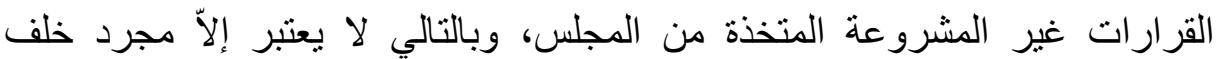

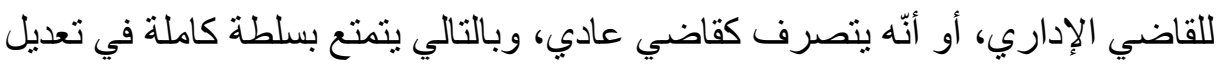
أو إلغاء قرار الإد مجلس المنافسة(20).

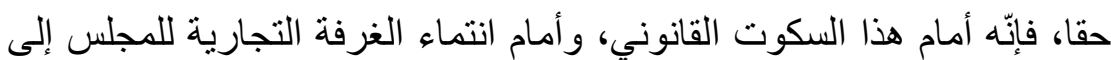

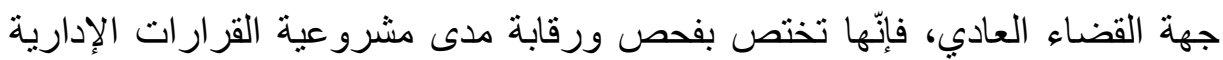

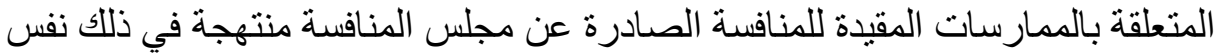

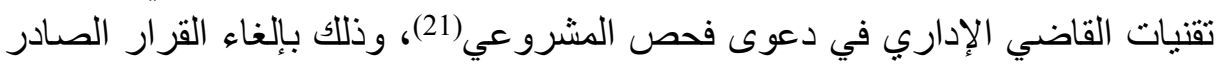

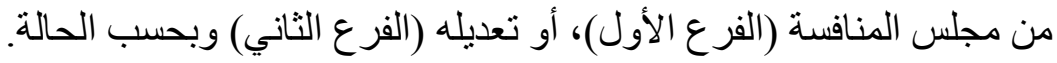

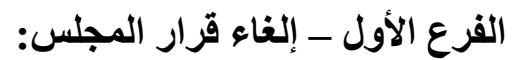

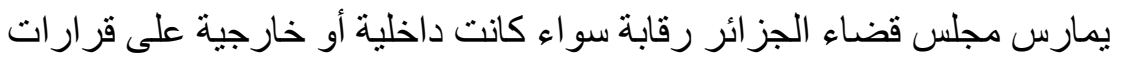

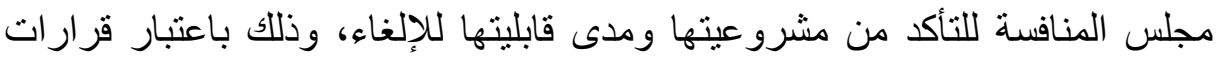

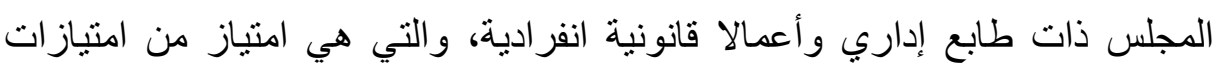

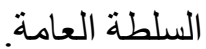

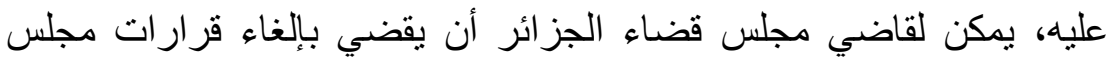

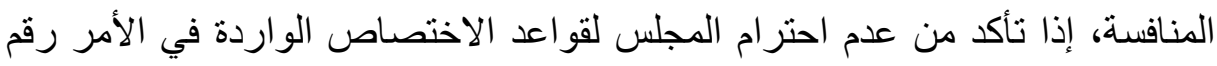

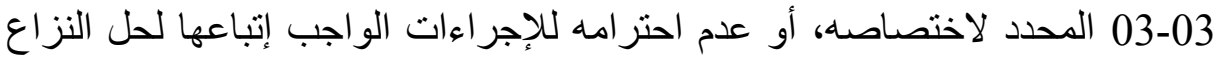
أمامه، لاسيما تللك المنظمة بموجب المرسوم الرئاسي رقم الداخلي لمجلس المنافسة(22).

\section{الفرع الثاني ـ تعديل قرار المجلس:}

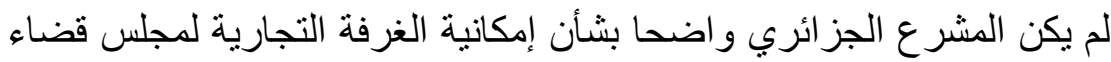

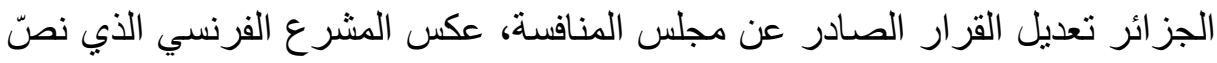

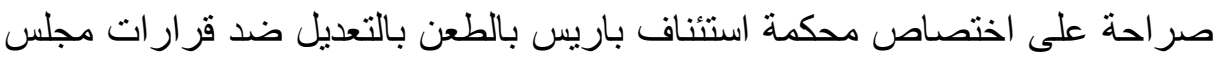

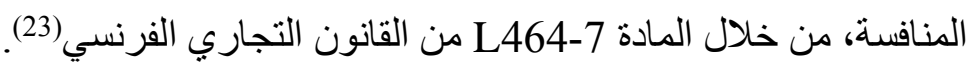

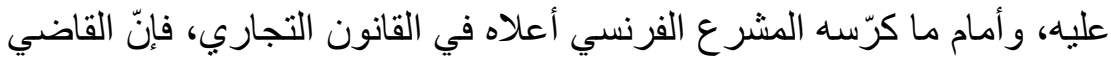

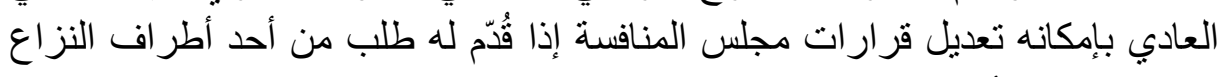

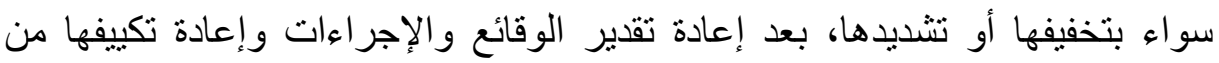


يمكن التوصل من كل ما سبق، إلى أنّ إنشاء مجلس المنافسة لا يُلغي أبدا دور القاضي في تطبيق قانون المنافسة، حيث توجد علئ علاقة تكامل بينها.

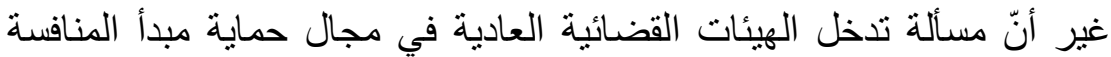

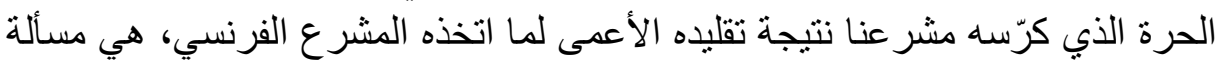

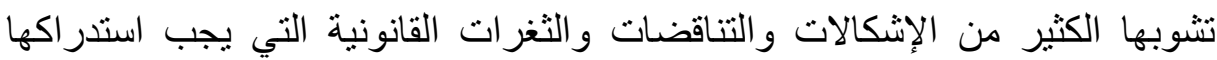
و التي نذكر منها:

- تناقض أحكام القانون العضوي رقم 98-01 المحدد لاختصاصات مجلس

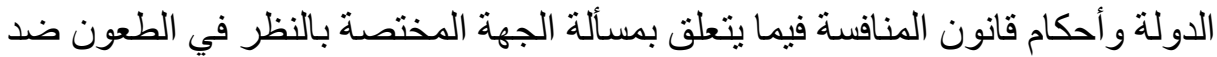

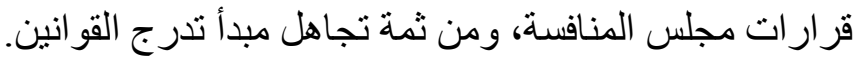

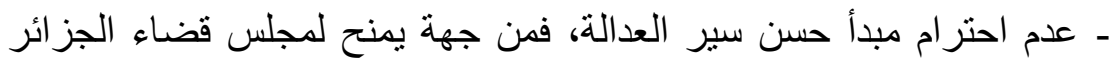
العاصمة اختصاص النظر في الطعون ضد قرارات مجلس المنافسة والمتعلقة

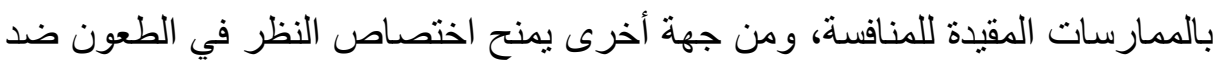

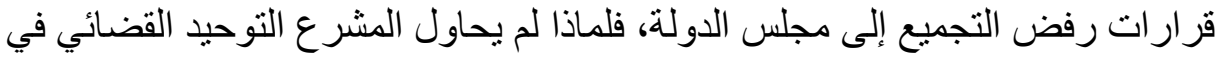

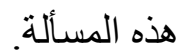

- عدم وضع إجراءات موحدة لحل منازعات مجلس المنافسة، فتارة ينظمها

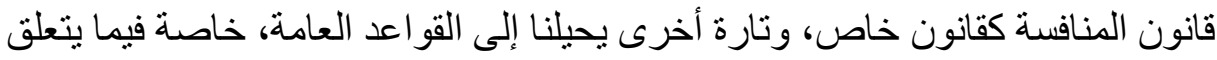

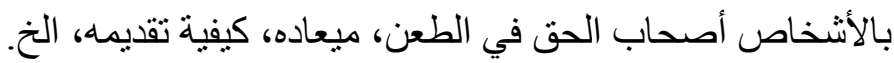

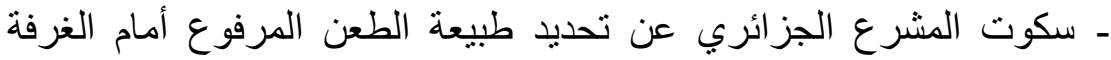

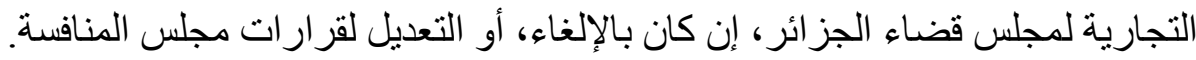
ـ عجز المدعي عن إثبات الممارسات المنافية للمنافسة.

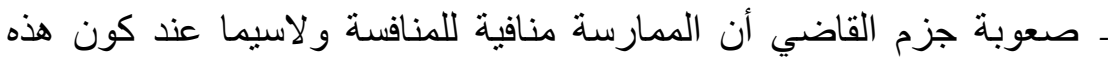
الأخيرة غير محسوسة أو كونها قليلة الثأن.

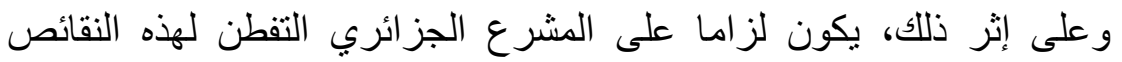
ومحاولة إعادة النظر في مسائل قانونية كثيرة و لاسيما منها: - وضع إجر اءات موحدة لحل مناز عات مجلس المنافسة،

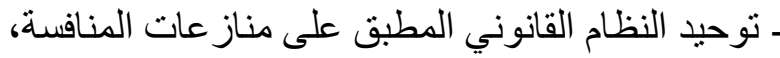

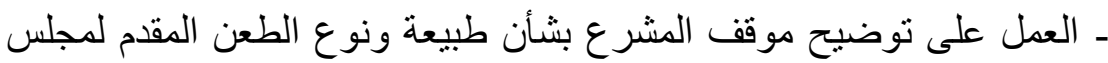
قضاء الجزائر العاصمة، - ضرورة تكريس حقيقي لحقوق الدفاع والضمانات القانونية المعمول بها أمام القضاء لمجلس المنافسة نفسه، و ذلك خوفا من تعسفه في استعمال السلطات المخولة لd

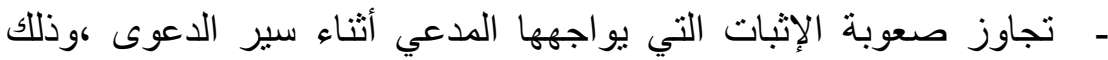

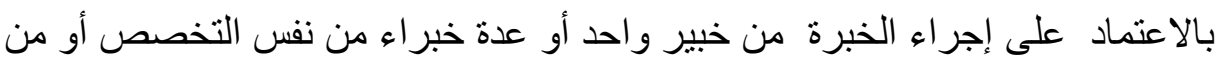
تخصصات مختلفة،

ـ الاستعانة بمجلس المنافسة لطلب رأيه في القضايا المعروضة على القاضي العادي مثلما تنص المادة 38 من الأمر رقم 03-03 المعدل والمتمم ،السابق الإشارة إليه، - دعوة القاضي إلى إجراء تحقيقات و الأمر بإحضار الخصوم شخصيا ل للحصول على توضيحات، 
ـ محاولة إعادة النظر في المنظومة القانونية الجزائرية لتفادي الاختلاف الذي

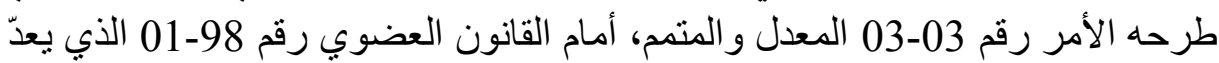

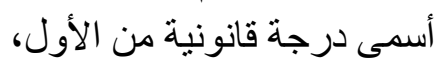

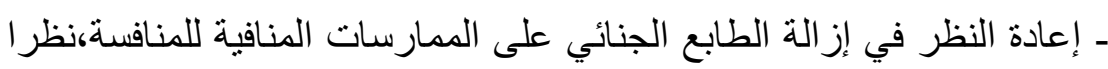
للاور الايجابي للعقوبات الجزائية في مجال المنافسة.

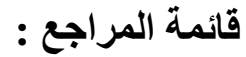
المجلات:

ZOUAIMIA Rachid, "Remarques critiques sur le contentieux des décisions du conseil de la concurrence en droit algérien", Revue du conseil d'Etat, $\mathrm{N}^{\circ}$ 7, 2005, p 36.

$$
\text { الكتب }
$$

, droit et économie de la - FRAISON-ROCHE Marrie-Anne régulation: les régulations économiques, légitimité et efficacité, Dalloz, Paris, 2004, p 183.

\section{الرسائل والمذكر ات الجامعية :}

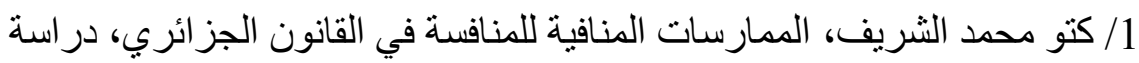

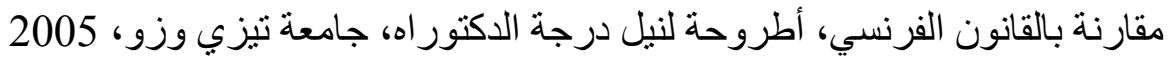

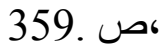

2/ خمايلية سمير، عن سلطة مجلس المنافسة في ضبط السوق، مذكرة لنيل شهادة

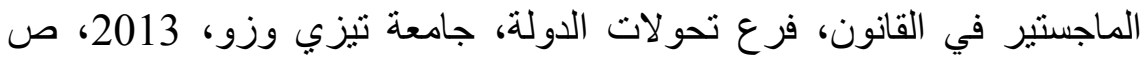

111.

3/ عمورة عبسى، النظام القانوني لمنازعات مجلس المنافسة، مذكرة لنيل شهادة

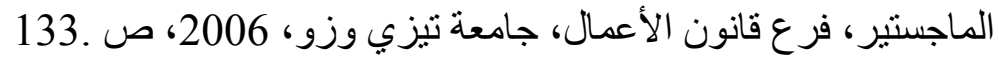

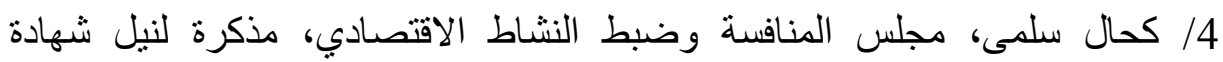

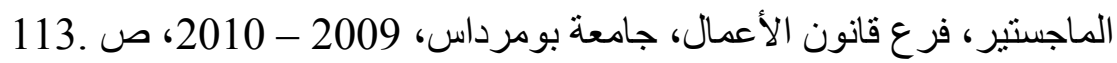

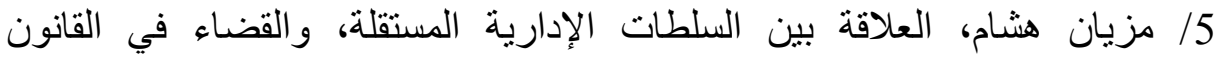
الجزائري، مذكرة لنيل شهادة الماجستير، فرع القانون التون العام، جامعة بجاية، ص

6/ موساوي ظريفة، دور الهيئات القضائية العادية في تطبيق قانون المنافسة، مذكرة لنيل شهادة الماجستير، فرع قانون المسؤولية المهنية، جامعة تيزي فئية وزون، 17. 2011 7/ يحياوي زهوة ويعقوبي كنزة، تداخل الاختصاص بين مجلس المنافسة و القضاء

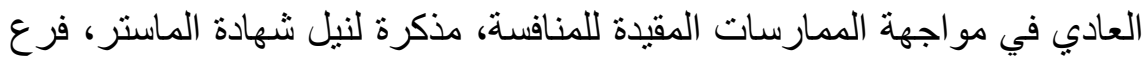

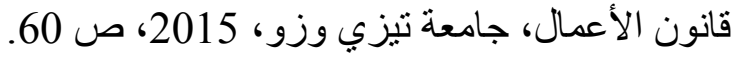

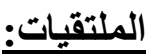


-بز غيش بوبكر ، "خصوصية إجر اءات الطعن في القرار ات الصادرة عن السلطات الصات

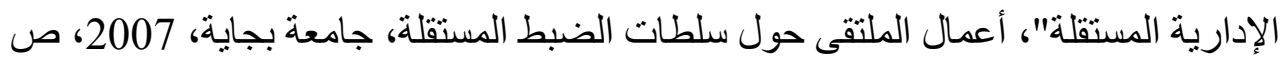

\section{النصوص التشرص القانونية:}

1/ أمر رقم 75-75 مؤرخ في 26 سبتمبر 1975، يتضمن القانون المدني، جريدة

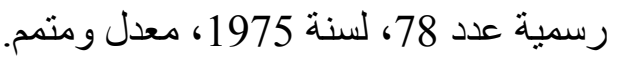

2/ أمر رقم 96-95 مؤرخ في 19 جانفي 1995، يتعلق بالمنافسة، جريدة رسمية عدد

09، صادر بتاريخ 22 فيفري 1995 (ملغنى). 195 (مئ.

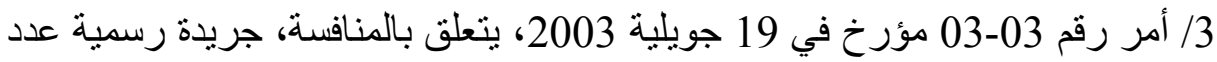

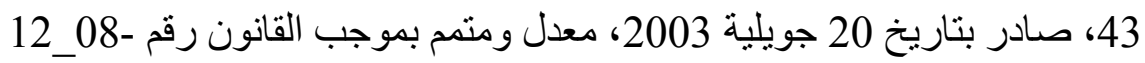

المؤرخ في 25 جوان 2008،جريدة رسمية عدد36، 36،صادر في 2003، 20دويلية 2008،والقانون رقم 10-05 المؤرخ في 15 15أوت 2008 2010،جريدة رسمية

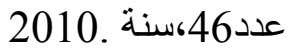

4/ قانون رقم 08-09 مؤرخ في 25 فيفري 2008، يتضدن قانون الإجراءات المدنية

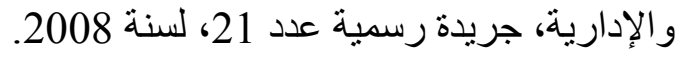

\section{النصوص التنظيمية :}

- مرسوم رئاسي رقم 96-44 مؤرخ في 17 جانفي 1996، يحدد النظام الداخلي لمجلس المنافسة، جريدة رسمية عدد 05، صادر في في 22 جانفي 1996.

\section{الهوامش:}

(1) - أمر رقم 03-03 مؤرخ في 19 جويلية 2003، يتعلق بالمنافسة، جريدة رسمية

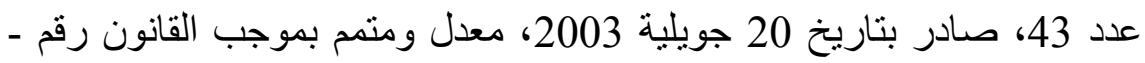

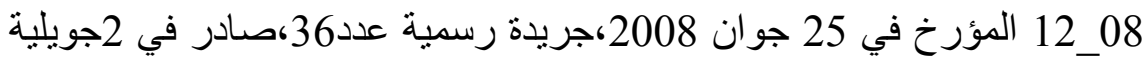
2008،والقانون رقم 10 10_05 المؤرخ في 15 15أوت 208 2010،جريدة رسمية عدد46،سنة 2010.

(2) - يحياوي زهوة ويعقوبي كنزة، تداخل الاختصاص بين مجلس المنافسة و القضاء

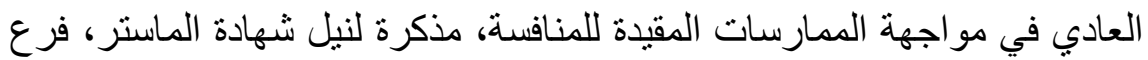

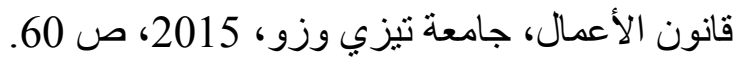

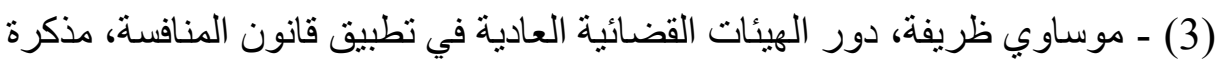

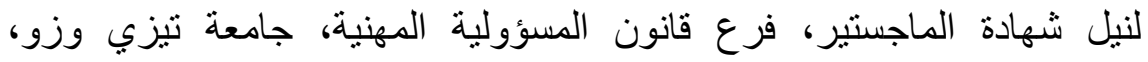

$$
\text { 2011 2011 2011 }
$$

(4) - كتو محمد الثريف، الممارسات المنافية للمنافسة في القانون الجزائري، دراسة

مقارنة بالقانون الفرنسي، أطروحة لنيل درجة الدكتوراه، جامعة تيزي وزو،

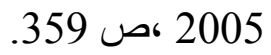

(5) - أمر رقم 75-58 مؤرخ في 26 سبتمبر 1975، يتضمن القانون المدني، جريدة

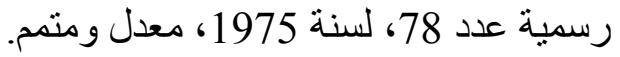


ـ كحال سلمى، مجلس المنافسة وضبط النشاط الاقتصادي، مذكرة لنيل شهادة

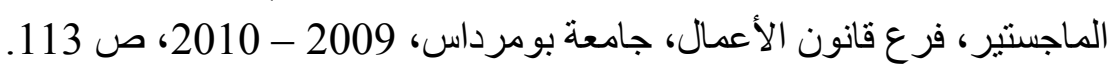

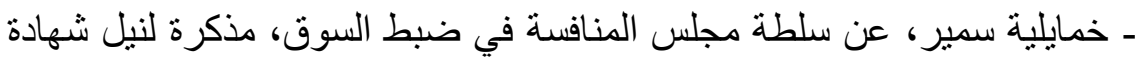

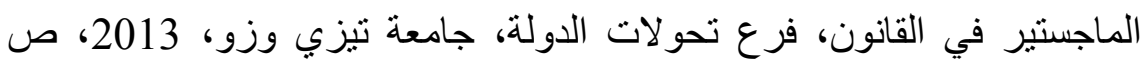

- موساوي ظريفة، مرجع سابق، ص 44 ـ 4 ـ

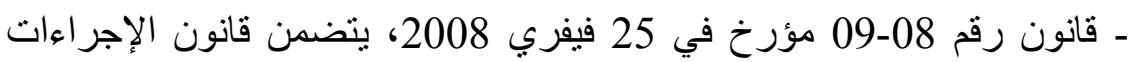

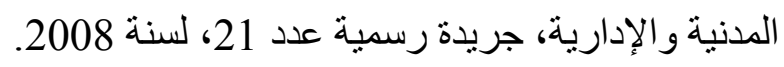

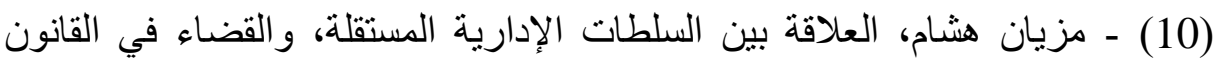

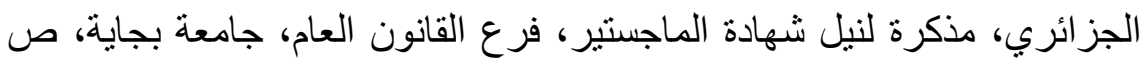

(11) - FRAISON-ROCHE Marrie-Anne, droit et économie de la régulation: les régulations économiques, légitimité et efficacité, Dalloz, Paris, 2004, p 183.

ـ أمر رقم 95-06 مؤرخ في 19 جانفي 1995، ينعلق بالمنافسة، جريدة رسمية

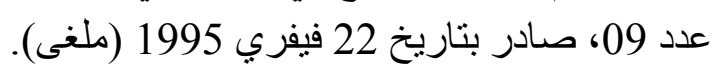

(13) - ZOUAIMIA Rachid, "Remarques critiques sur le contentieux des décisions du conseil de la concurrence en droit algérien", Revue du conseil d'Etat, $N^{\circ} 7,2005$, p 36.

(14) - تجدر الإشارة هنا إلى تعديل هذه المادة - أب 1/63 - بموجب المادة 31 من

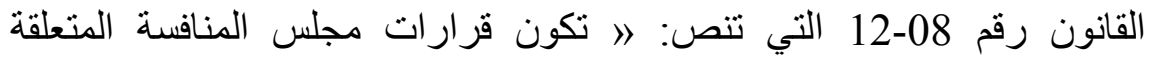

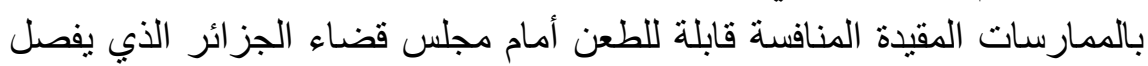

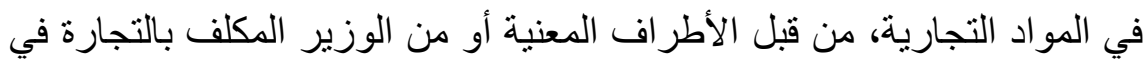

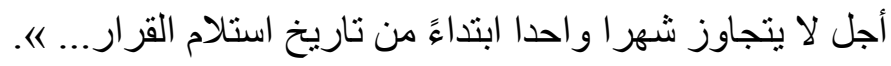
- قانون رقم 08-12 مؤرخ في 25 جوان 2008، جريدة رسمية عدد 36، لسنة

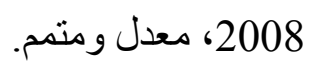

(15) - عمورة عيسى، النظام القانوني لمناز عات مجلس المنافسة، مذكرة لنيل شهادة

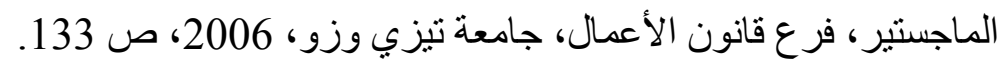

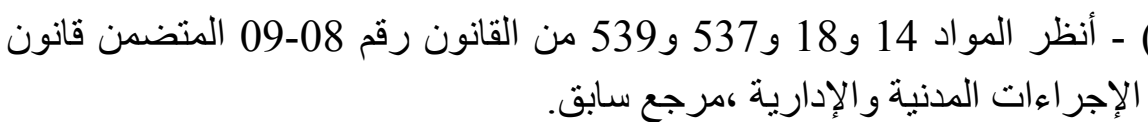

(17) - أنظر المواد 12، 13، 22، 23 و 25 من قانون الإجراءات الأن المدنية والإدارية،

$$
\text { مرجع نفسه. }
$$

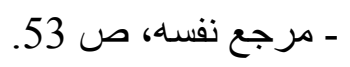

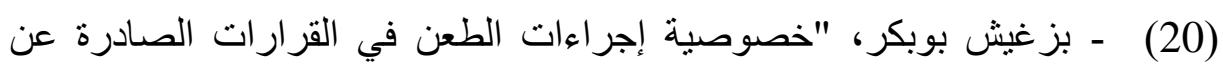

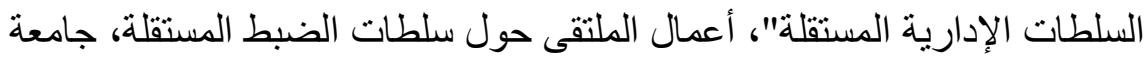




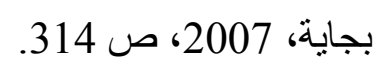

(21) - ZOUAIMIA Rachid, op.cit, p 38.

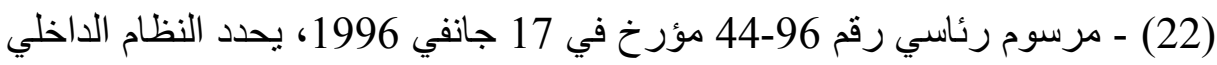

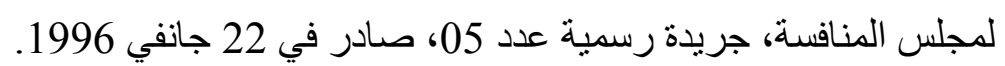

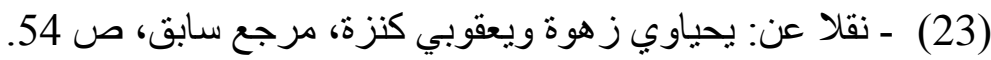

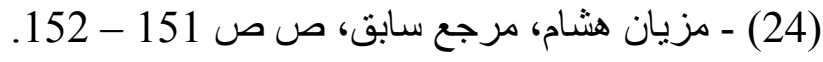

